\title{
Technical Note: 30 years of HIRS data of upper tropospheric humidity
}

\author{
K. Gierens ${ }^{1}$, K. Eleftheratos ${ }^{2}$, and L. Shi ${ }^{3}$ \\ ${ }^{1}$ Deutsches Zentrum für Luft- und Raumfahrt, Institut für Physik der Atmosphäre, Oberpfaffenhofen, Germany \\ ${ }^{2}$ Faculty of Geology and Geoenvironment, University of Athens, Athens, Greece \\ ${ }^{3}$ National Climatic Data Center, NOAA, Asheville, NC, USA \\ Correspondence to: K. Gierens (klaus.gierens@dlr.de)
}

Received: 21 January 2014 - Published in Atmos. Chem. Phys. Discuss.: 5 March 2014

Revised: 4 June 2014 - Accepted: 20 June 2014 - Published: 28 July 2014

\begin{abstract}
We use 30 years of intercalibrated HIRS (HighResolution Infrared Radiation Sounder) data to produce a 30year data set of upper tropospheric humidity with respect to ice $\left(\mathrm{UTH}_{\mathrm{i}}\right)$. Since the required brightness temperatures (channels 12 and $6, T_{12}$ and $T_{6}$ ) are intercalibrated to different versions of the HIRS sensors (HIRS/2 and HIRS/4) it is necessary to convert the channel 6 brightness temperatures which are intercalibrated to HIRS/4 into equivalent brightness temperatures intercalibrated to HIRS/2, which is achieved using a linear regression. Using the new regression coefficients we produce daily files of $\mathrm{UTH}_{\mathrm{i}}, T_{12}$ and $T_{6}$, for each NOAA satellite and METOP-A (Meteorological Operational Satellite Programme), which carry the HIRS instrument. From this we calculate daily and monthly means in $2.5^{\circ} \times 2.5^{\circ}$ resolution for the northern midlatitude zone $30-60^{\circ} \mathrm{N}$. As a first application we calculate decadal means of $\mathrm{UTH}_{\mathrm{i}}$ and the brightness temperatures for the two decades 1980-1989 and 2000-2009. We find that the humidity mainly increased from the 1980 s to the 2000 s and that this increase is highly statistically significant in large regions of the considered midlatitude belt. The main reason for this result and its statistical significance is the corresponding increase of the $T_{12}$ variance. Changes of the mean brightness temperatures are less significant.
\end{abstract}

\section{Introduction}

The detection of climate change is often hampered by the small signal-to-noise ratio in time series of climate data. The signal, that is often a small trend, can be and is usually superimposed by a mixture of oscillatory signals (periodic, quasi-periodic, and unperiodic), singular signals (e.g. caused by volcano eruptions) and random noise (e.g. caused by nonsystematic measurement errors, see for instance Zerefos et al., 2012). Generally long (typically decades) time series of data are required for application of sophisticated mathematical filter methods such that a trend can not only be detected but also stated with some statistical confidence (Weatherhead et al., 1998).

In the field of global satellite data analysis there is only one source of data that provides such long time series, that is the suite of instruments on the NOAA series of satellites, including the HIRS (High-Resolution Infrared Radiation Sounder) radiometers. Meteosat satellites provide similar long time series, but not with global coverage. Nowadays also the European METOP (Meteorological Operational Satellite Programme) satellites carry the HIRS instrument and thus the HIRS data set currently spans over 30 years. Unfortunately, there have been changes to the HIRS instrument over the years (e.g. channel frequencies; filter functions; the instantaneous geometric field of view, IGFOV, changed from HIRS version 2 to the current HIRS version 4; and the IGFOV changed from 20 to $10 \mathrm{~km}$ ) such that measurements from different satellites cannot be immediately combined together to form a long time series. Therefore it was necessary to foot measurements of different satellites on a common base, that is, to intercalibrate the data from all the satellites. This has been done in recent years for longwave channels of the HIRS instrument (e.g. Shi et al., 2008; Shi and Bates, 2011; Shi, 2013; Chen et al., 2013), such that one can now work with intercalibrated data from more than 30 years. 
Our special interest is to look for changes in upper tropospheric humidity in the long term. For that purpose we use the method developed by Jackson and Bates (2001), based on fundamental work by Soden and Bretherton (1993). The upper tropospheric humidity, UTH, can be derived from the measured brightness temperatures in HIRS channels 12 (central wave numbers $1480 \mathrm{~cm}^{-1}$ for HIRS/2 and $1530 \mathrm{~cm}^{-1}$ for HIRS/4) and 6 (central wave number $733 \mathrm{~cm}^{-1}$ for both HIRS/2 and HIRS/4) using the formula

$$
\mathrm{UTH}=\frac{\exp \left(a+b T_{12}\right)}{a^{\prime}+b^{\prime} T_{6}},
$$

with regression coefficients $a, b, a^{\prime}, b^{\prime}$ determined by Jackson and Bates (2001, their Table 2). In this equation, $T_{12}$ is essentially a measurement of the water vapour concentration in the free troposphere while $T_{6}$ is a corresponding temperature measurement, that is, the formula combines the usual ingredients for the determination of a relative humidity. The reader is referred to Jackson and Bates (2001) for details of the derivation. The coefficients have been given for both UTH with respect to liquid water, $\mathrm{UTH}_{\mathrm{w}}$, and with respect to ice, $\mathrm{UTH}_{\mathrm{i}}$. A result $\mathrm{UTH}_{\mathrm{i}}>100 \%$ signifies ice supersaturation. As the weighting kernels of HIRS channel 12 are sensitive to a deep atmospheric layer roughly between 300 and $500 \mathrm{hPa}$, UTH has to be interpreted as a kind of mean relative humidity over that layer, and $\mathrm{UTH}_{\mathrm{i}}>100 \%$ only arises when most of this thick layer is supersaturated which occurs only rarely; only few percent of ice supersaturated layers reach a depth of $3 \mathrm{~km}$ and more (cf. thickness statistics in Spichtinger et al., 2003a; Treffeisen et al., 2007; Rädel and Shine, 2007; Dickson et al., 2010).

Jackson and Bates (2001) determined their regression coefficients for the HIRS version 2 (HIRS/2) instrument on NOAA-7, but the recent intercalibration of HIRS channels was based on HIRS/4 on METOP-A. Thus, we either have to determine new regression coefficients for the brightness temperatures measured with HIRS/4 (in the following written $T_{12 / 4}$ and $T_{6 / 4}$ ) or, alternatively, we have to determine a method to derive the HIRS/2 brightness temperatures from the HIRS/4 ones. As the latter alternative is the simpler, we follow it. Fortunately, an intercalibrated data set of $T_{12 / 2}$ has been prepared by Shi and Bates (2011) such that we can concentrate on channel 6 now which we take from the data set prepared by Shi et al. (2008). Comparisons of the brightness temperatures from NOAA-14 with NOAA-15 (transition from HIRS/2 to HIRS/3) and from NOAA-17 with METOP-A (transition from HIRS/3 to HIRS/4) showed that channel values of $T_{6}$ are very similar across the different instrument versions, such that a very simple solution to our problem would be to ignore these differences and assume that $\hat{T}_{6 / 2}=T_{6 / 4}$ (the hat over $T$ signifies an estimate). This would induce rms (root mean square) errors of the order $0.05 \%$ (about $0.125 \mathrm{~K}$ ). Although this is already very good we decided to reduce the rms error further by performing a linear regression.
In the following we develop the regression of $T_{6 / 2}$ on $T_{6 / 4}$ and introduce simple quality checks. Using this method we have produced a new $\mathrm{UTH}_{\mathrm{i}}$ data set that shares the file structure with the data set of intercalibrated brightness temperatures (sorted with respect to satellite, year and date). We note that a new $\mathrm{UTH}_{\mathrm{w}}$ data set can be produced with the same method but we have not yet done that. As we are eventually interested in ice supersaturation (Gierens et al., 2004, 2012) we restrict our data currently to a latitude band from 30 to $60^{\circ} \mathrm{N}$, because data from other satellites showed almost no ice supersaturation in the $300-500 \mathrm{hPa}$ layer within the tropical latitude band (see for instance Spichtinger et al., 2003b; Gettelman et al., 2006). The first applications of this new data set are presented in Sect. 3 before a summary and an outlook to further plans is given in the final Sect. 4 .

\section{Technical implementation}

The regression of $T_{6 / 2}$ on $T_{6 / 4}$ was developed using all daily data from complete years of NOAA-12 (1992-1996). We use NOAA-12 because the HIRS/2 channel 12 data we use (from Shi and Bates, 2011) were intercalibrated to NOAA12 , therefore it makes sense to also calibrate channel 6 to NOAA-12. During the work on the channel 12 intersatellite calibration several years ago the base satellite was determined in consideration of several factors. First, the satellite needs to have a sufficient length of observation, preferably longer than 5 years. Second, the intercalibrated values are close to those of the base satellite used in an earlier work of Jackson and Bates (2001) for easier comparison. And third, the satellite's drift is relatively small compared to others in the HIRS $/ 2$ series. From a combination of these factors, NOAA-12 was chosen as the base satellite in the study of Shi and Bates (2011).

The data set contains the intercalibrated brightness temperatures $T_{6 / 4}$ and in parallel the original ones measured with the NOAA-12 HIRS/2 instrument, i.e. $T_{6 / 2}$. Figures 1 and 3 of Shi (2013) indicate that a linear regression might be sufficient, such that we can try

$$
\begin{aligned}
& \hat{T}_{6 / 2}(\lambda, \beta, d)=I+S T_{6 / 4}(\lambda, \beta, d), \\
& \varepsilon(\lambda, \beta, d)=T_{6 / 2}(\lambda, \beta, d)-\hat{T}_{6 / 2}(\lambda, \beta, d) .
\end{aligned}
$$

We remind that the hat over the $T$ is used to distinguish an estimated brightness temperature from the original value. The geographical coordinates longitude and latitude are given as $\lambda$ and $\beta$ and $d$ is the day of the year (1-365 or 366). $I$ and $S$ are intercept and slope of the regression, respectively. $\varepsilon$ is the residuum, that is, the difference between the original $T_{6 / 2}$ and the estimated one, $\hat{T}_{6 / 2}$, which eventually has been checked to have zero mean and no obvious structure (i.e. to contain no strong signals) after applying the regression. Although some structure remains in the residuum, induced 


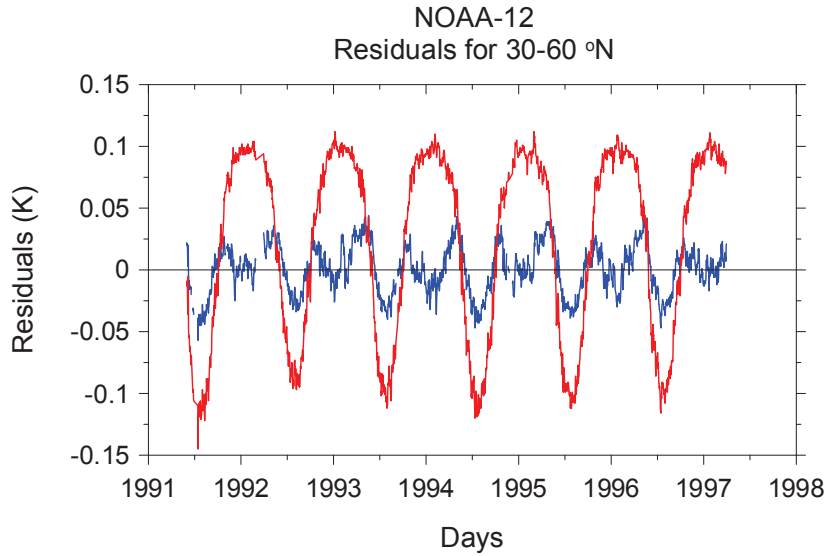

Figure 1. Residuals $T_{6 / 2}-\hat{T}_{6 / 2}$ (blue curve) and $T_{6 / 2}-T_{6 / 4}$ (red curve) averaged over the indicated latitude band and for each day of NOAA-12 operation.

probably by an annual variation of $T_{6 / 2}-T_{6 / 4}$, we decided to not use a more sophisticated regression because the amplitude of the signal is small and only about a third of the amplitude of $T_{6 / 2}-T_{6 / 4}$. Figure 1 shows that the residual errors are generally smaller than $50 \mathrm{mK}$. This is smaller than the channel 6 noise equivalent radiance of $0.24 \mathrm{~mW}\left(\mathrm{~m}^{2} \mathrm{sr} \mathrm{cm}^{-1}\right)^{-1}$ (equivalent to $54 \mathrm{mK}$, see NOAA and NASA-GSFC, 2008). Using more than 36 million data records we find for intercept and slope:

$I=2.57981, \quad S=0.98978$.

Because the residuals $T_{6 / 2}-\hat{T}_{6 / 2}$ are typically three times smaller than the difference $T_{6 / 2}-T_{6 / 4}$, as shown in Fig. 1, the error induced on the retrieval of $\mathrm{UTH}_{\mathrm{i}}$ via the factor $1 / P_{\mathrm{H}}$ is smaller when the regression is used than when the difference between $T_{6 / 2}$ and $T_{6 / 4}$ is ignored. The rms error is $0.03 \%$. Figure 2 shows this contribution to the overall uncertainty (for the derivation of the error estimates, see the Appendix). Note that the uncertainty of $T_{6 / 4}$ itself is not considered in this figure.

In their original method Jackson and Bates (2001) discarded all measurements where $T_{6 / 2}-T_{4 / 2}<20 \mathrm{~K}$, and Gierens et al. (2004) followed this practice. Generally, the relation between channel 4 brightness temperatures from different HIRS designs differs much more from a $y=x$ line than for channel 6 (Figs. 1 and 3 of Shi, 2013). Also the annual variation of the difference $T_{4 / 2}-T_{4 / 4}$ is less smooth than that of the channel 6 brightness temperatures. Thus, we decided to not try a regression for channel 4 . Instead, we replace the original criterion by Jackson and Bates (2001) with a corresponding one for HIRS/4, i.e. $T_{6 / 4}-T_{4 / 4}<20 \mathrm{~K}$, and additionally we compute the upper tropospheric humidity with respect to liquid water, $\mathrm{UTH}_{\mathrm{w}}$, and discard all measurements with $\mathrm{UTH}_{\mathrm{w}}>100 \%$. The latter is only a very minor fraction of the order $10^{-4}$ and less of the data that we checked (January and July 1980 and 2000).

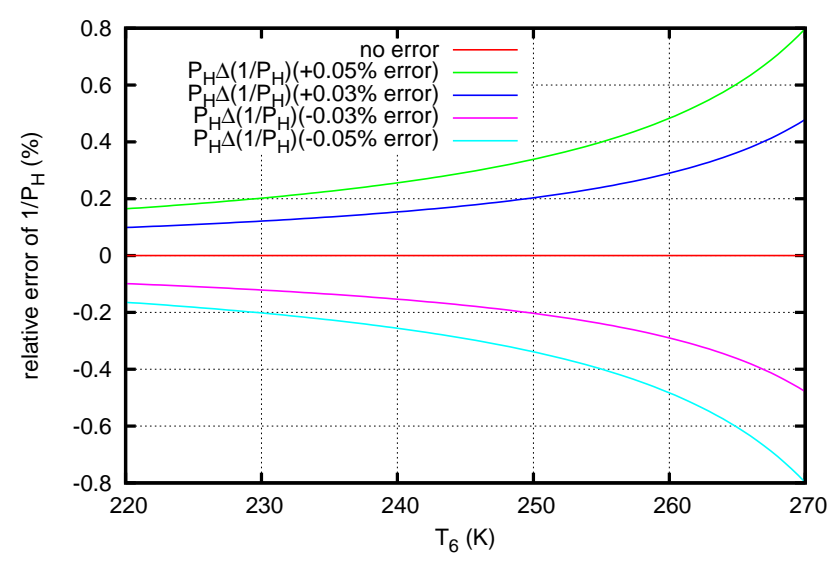

Figure 2. Relative error incurred to the prefactor $\left(1 / P_{H}\right)$ of the $\mathrm{UTH}_{\mathrm{i}}$ calculation via errors in the estimated channel 6 brightness temperature, that is, due to the regression with $T_{6 / 4}$. Measurement errors of $T_{6 / 4}$ are not taken into account for this calculation. The relative error is $P_{H} \Delta\left(1 / P_{H}\right)=-\left[\left(b^{\prime} T_{6}\right) /\left(a^{\prime}+b^{\prime} T_{6}\right)\right] \cdot\left[\left(\Delta T_{6}\right) / T_{6}\right]$ The red line represents the true values $(0 \%$ error), the other lines show the relative errors of $1 / P_{H}$ for $\pm 0.05 \%$ (outer lines in green and light blue) and for $\pm 0.03 \%$ error in $T_{6}$ (inner dark blue and violet curves).

As stated above, the analysis is restricted to an extratropical latitude band where we expect some ice supersaturation $\left(30-60^{\circ} \mathrm{N}\right)$, all brightness temperatures are cloudcleared (that is, we use only clear-sky measurements), and although all data used in this study are limb-corrected (Jackson and Bates, 2000) we use from the almost $50^{\circ}$ swath angle of the HIRS instruments only the central $33^{\circ}$ (scan positions 11-46).

For potential users interested in UTH with respect to either water or ice we can also reformulate Eq. (1) so that $T_{6 / 4}$ appears directly, that is,

$\mathrm{UTH}=\frac{\exp \left(a+b T_{12 / 2}\right)}{a^{\prime}+b^{\prime}\left(I+S T_{6 / 4}\right)}=\frac{\exp \left(a+b T_{12 / 2}\right)}{a^{\prime \prime}+b^{\prime \prime} T_{6 / 4}}$,

with $a^{\prime \prime}=a^{\prime}+b^{\prime} I$ and $b^{\prime \prime}=b^{\prime} S$, where $a^{\prime}$ and $b^{\prime}$ can be obtained from Jackson and Bates (2001) and $I$ and $S$ are given above.

\section{First exemplary results}

As a first application of the $\mathrm{UTH}_{\mathrm{i}}$ data we compute decadal means of the periods 1980-1989 and 2000-2009 for the chosen zone of $30-60^{\circ} \mathrm{N}$ and with $2.5^{\circ} \times 2.5^{\circ}$ spatial resolution. These means together with a map of their differences are shown in Fig. 3. We find a general increase in $\mathrm{UTH}_{\mathrm{i}}$ from the subtropics towards the arctic, typically with values lower than $30 \%$ at $30^{\circ} \mathrm{N}$ and values above $40 \%$ at $60^{\circ} \mathrm{N}$ for both periods. This behaviour is expected. From that figure it also appears that $\mathrm{UTH}_{\mathrm{i}}$ has increased at most locations from the 1980 s to the 2000s. The increase is however nowhere larger 

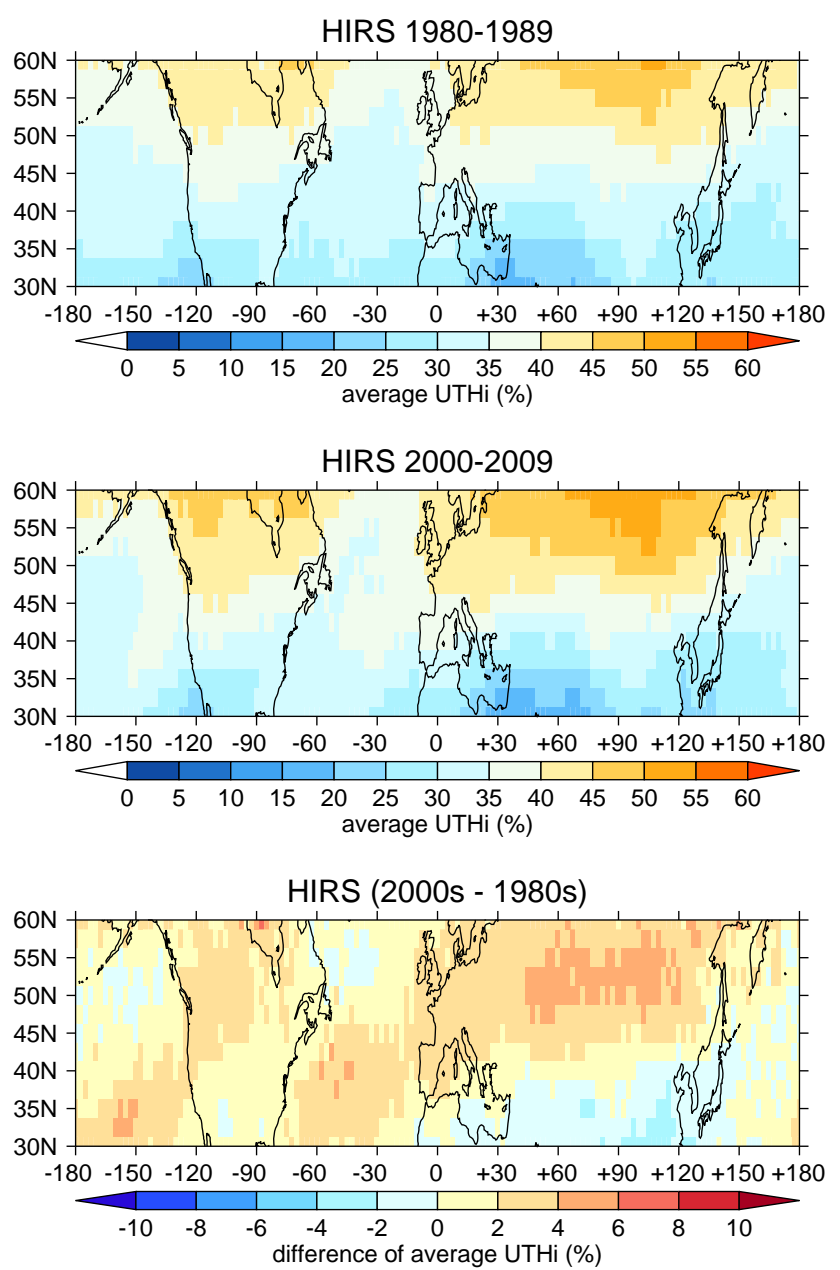

Figure 3. Decadal means of upper tropospheric humidity with respect to ice for the decades 1980-1989 and 2000-2009 and the difference of these means from all available HIRS observations during the respective periods. Spatial resolution is $2.5^{\circ} \times 2.5^{\circ}$ and shown is the zone $30-60^{\circ} \mathrm{N}$.

than a few percent and some regions even show a slight decrease in humidity. Before we start interpreting these changes we look at their statistical significance in Fig. 4. We show in the upper panel the standard deviations of $\mathrm{UTH}_{\mathrm{i}}$ for the first decade, 1980-1989, based on the monthly averages in each grid box. These are mostly less than $10 \%$ (in relative humidity units), but over Siberia and the Canadian Arctic islands and between Turkey, Middle East and China there are larger variances. The middle panel shows how these standard deviations have changed from the earlier to the later (2000-2009) decade. It appears that not only have the mean values increased, but the variances as well. The lower panel shows the statistical significance values of the $\mathrm{UTH}_{\mathrm{i}}$ differences of the mean values based on a $t$ test for each pixel. Because of the changed variances we used a $t$ test that accounts for different variances (IDL (Interactive Data Language) $t$ test routine has a corresponding switch). Trials with a simple $t$ test (assuming

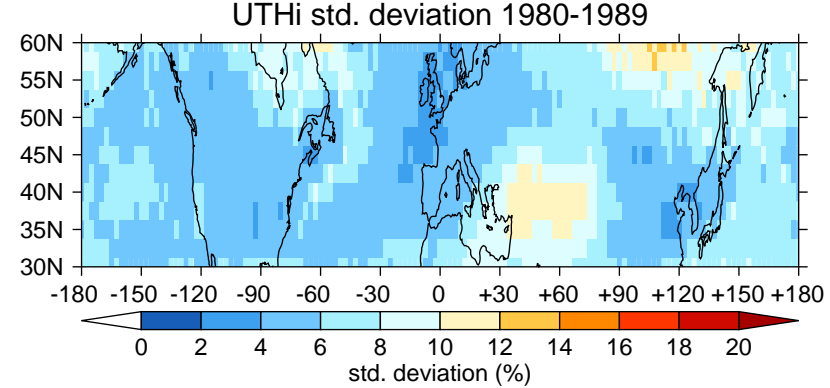

Difference of UTHi std. deviation (2000s - 1980s)

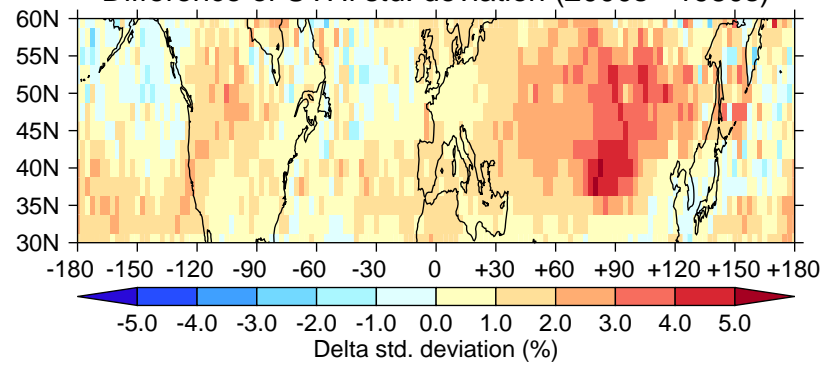

Levels of significance for the difference of the two means

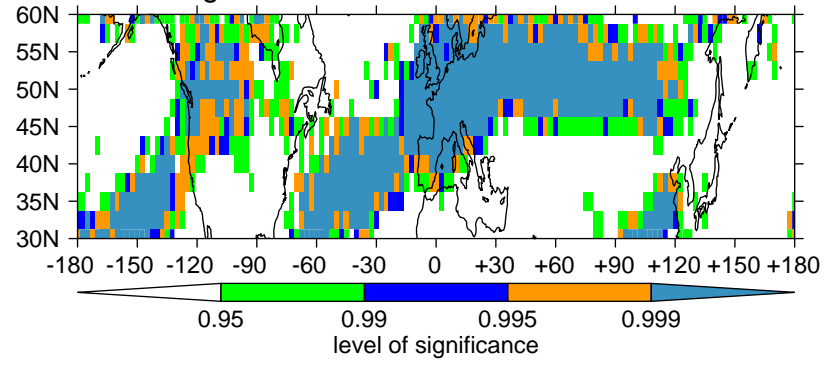

Figure 4. Top panel: map of standard deviations of upper tropospheric humidity based on monthly averages for the decade 19801989. Middle panel: map of the change of these standard variations between 2000-2009 and 1980-1989. Bottom panel: statistical significance values for the difference of two decadal means of $\mathrm{UTH}_{\mathrm{i}}$ based on $t$ tests with unequal variances for each pixel. Resolution as in Fig. 3.

equal variances) and a nonparametric (Mann-Whitney $U$ ) test all gave similar results. Evidently there are large regions with highly significant increases of the mean $\mathrm{UTH}_{\mathrm{i}}$. Insignificant values are found predominantly in regions with large variance.

Similar investigations can be done with the two brightness temperatures involved. Decadal averages and their respective differences are shown in Figs. 5 and 7, the standard deviations, their change over two decades, and statistical significance values of the changes of the means based on monthly averages are presented in Figs. 6 and 8, respectively. Obviously, $T_{6}$ decreased almost everywhere, while $T_{12}$ shows increases and decreases. This alone would hardly explain an average increase of $\mathrm{UTH}_{\mathrm{i}}$, as we can see from the equations provided in the Appendix when we insert the decadal 

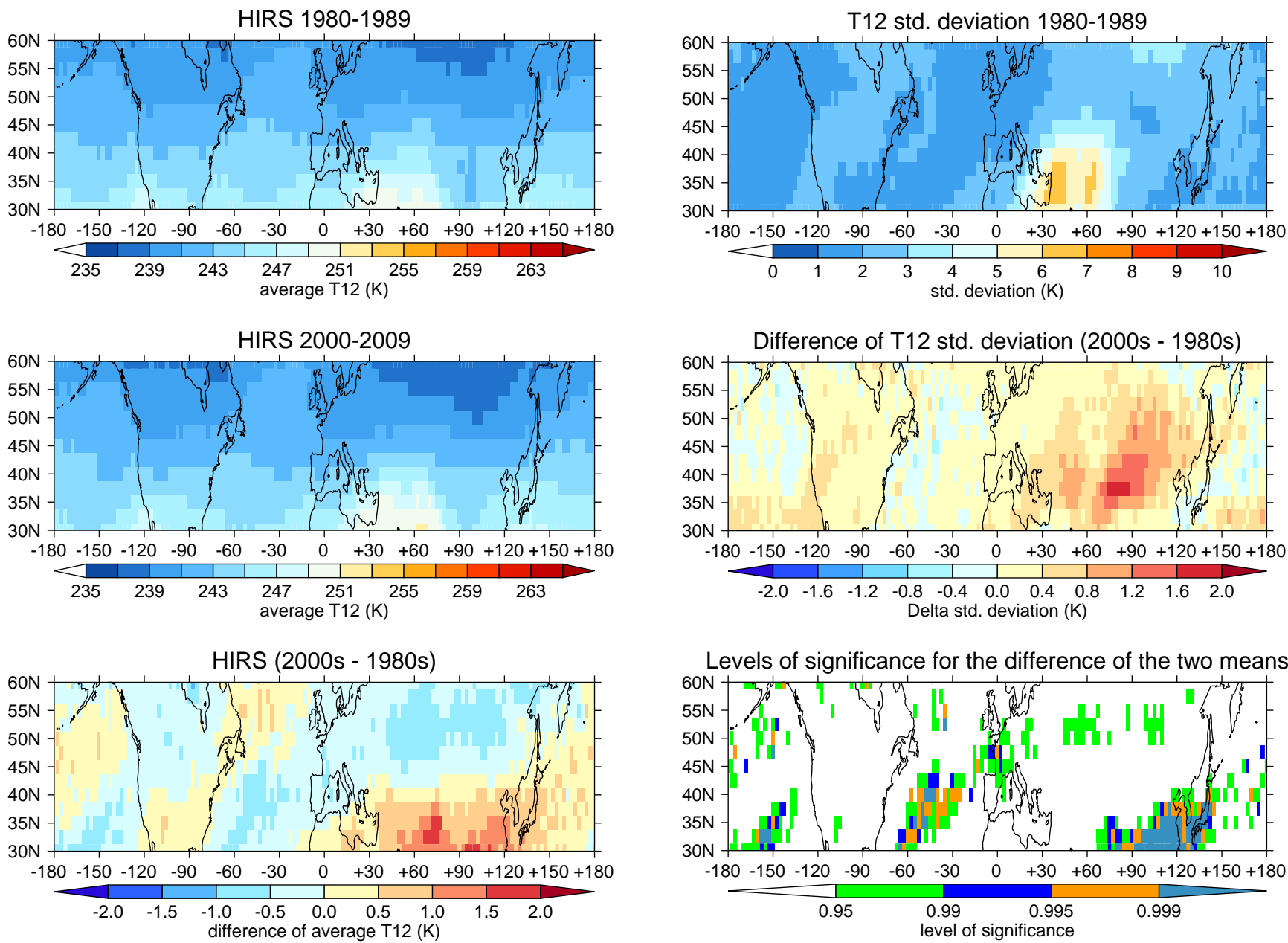

Levels of significance for the difference of the two means

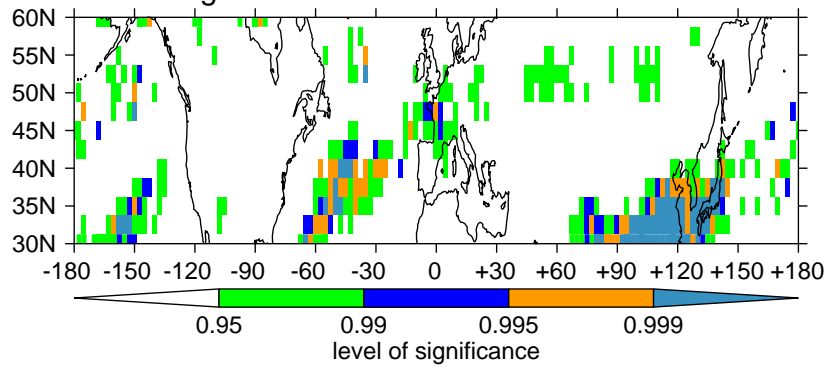

Figure 5. Decadal means of channel 12 brightness temperature for the decades 1980-1989 and 2000-2009 and the difference of these means from all available HIRS observations during the respective periods. Resolution as in Fig. 3.

differences of the brightness temperatures for $\Delta T_{6}$ and $\Delta T_{12}$. Moreover, the brightness temperature changes are at many locations insignificant where we have significant changes of $\mathrm{UTH}_{\mathrm{i}}$ in spite of this fact. In order to understand this surprising result we have performed Monte Carlo experiments (that is, made statistical tests on random series of brightness temperatures and resulting humidity values where we knew the distribution from which the brightness temperatures were drawn). It turned out that significant changes in $\mathrm{UTH}_{\mathrm{i}}$ can result from increase of the $T_{12}$ variance combined with a decrease of its mean. Changes in the distribution of $T_{6}$ are less important (Eqs. A2 and A3 show that a change of $T_{12}$ changes $\mathrm{UTH}_{\mathrm{i}}$ about five times as much as the same change of $T_{6}$ ). That an increase of the variance of $T_{12}$ can lead to an increase of the mean $\mathrm{UTH}_{\mathrm{i}}$ is understandable from the nonlinear functional dependence between these two quantities: the increase of $\mathrm{UTH}_{\mathrm{i}}$ due to a negative $\Delta T_{12}$ is larger than the corresponding decrease due to the same but positive

Figure 6. Top panel: map of standard deviations of channel 12 brightness temperature based on monthly averages for the decade 1980-1989. Middle panel: map of the change of these standard variations between 2000-2009 and 1980-1989. Bottom panel: statistical significance values for the difference of two decadal means of $T_{12}$ based on $t$ tests with unequal variances for each pixel. Resolution as in Fig. 3.

$\Delta T_{12}$. Increases of $\mathrm{UTH}_{\mathrm{i}}$ are enhanced when $T_{12}$ means are decreasing together with an increasing variance, while decreases of $\mathrm{UTH}_{\mathrm{i}}$ are damped when $T_{12}$ means are increasing together with an increasing variance.

Indeed, over mid-Asia, along the latitude belt centred at about $50^{\circ} \mathrm{N}$ for example, it appears that there are statistically significant increases in $\mathrm{UTH}_{\mathrm{i}}$ from the 1980s to the 2000s which are consistent with decreasing $T_{12}$ means and increasing $T_{12}$ variances. However, insignificant decreases in $\mathrm{UTH}_{\mathrm{i}}$ over southern Asia (at 30-35 $\mathrm{N}$ ) are associated with increasing $T_{12}$ means and increasing $T_{12}$ variances over those regions. It should be noted here that significant increases in $\mathrm{UTH}_{\mathrm{i}}$ may also result from significant decreases in $T_{12}$ with small changes in $T_{12}$ variances (e.g. over the southern part of the North Atlantic), whereas significant $\mathrm{UTH}_{\mathrm{i}}$ decreases 

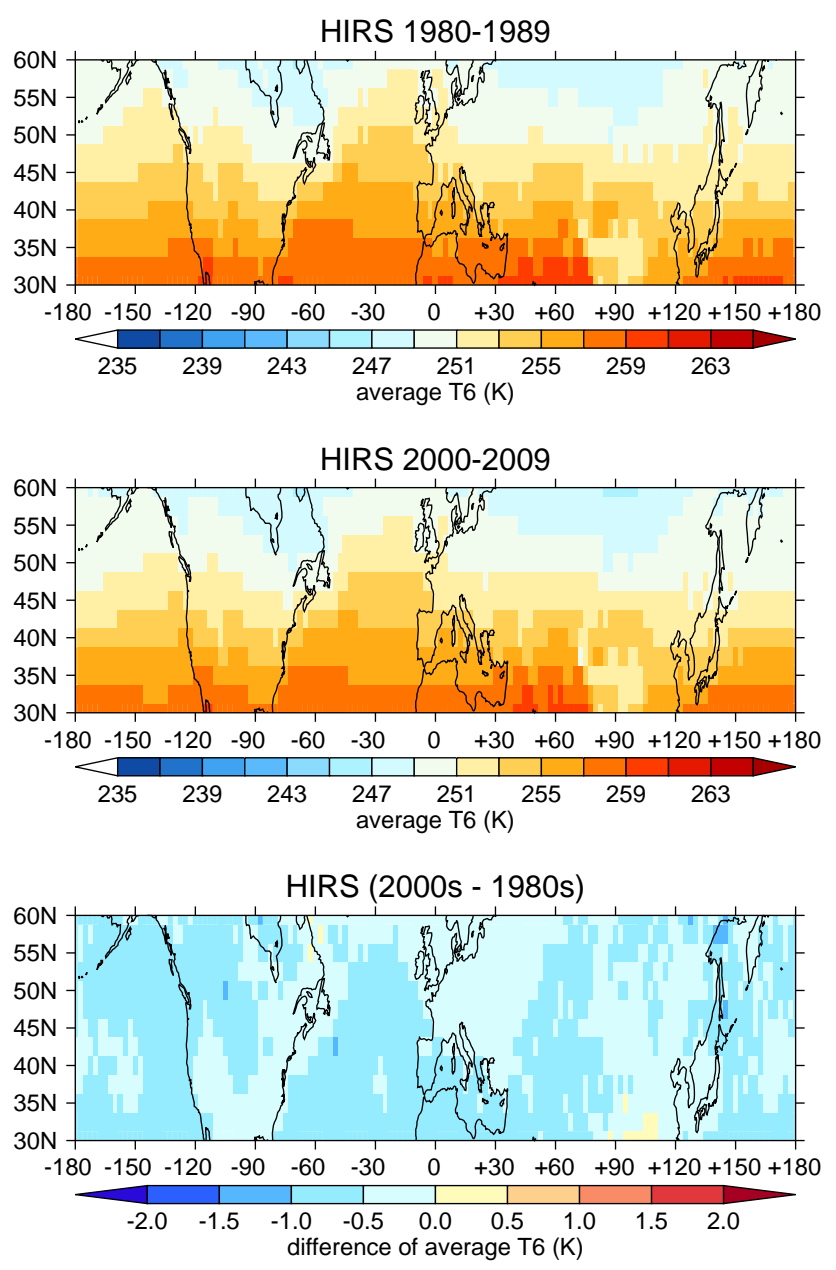

Figure 7. As Fig. 5, but for $T_{6}$.

may result from significant increases in $T_{12}$ for example over southeast Asia around $30^{\circ} \mathrm{N}, 120^{\circ} \mathrm{E}$.

The increase of temperature variances is also visible in reanalysis data (ERA Interim and NCEP). We found increased temperature variability on all levels from 300 to $700 \mathrm{hPa}$ in those regions where the increase of upper tropospheric humidity is statistically significant (not shown). The temperatures themselves increase almost everywhere on these levels, consistent with observations and analyses of global warming.

Systematic diurnal temperature variations (daily temperature range) in combination with drifting satellite overpass times can pretend changing brightness temperatures that have no climatological basis. Thus, we have to check whether such effects could corrupt our analysis. Fortunately this is rather improbable. The diurnal variations of both $T_{6}$ and $T_{12}$ are generally small (no more than $0.2 \mathrm{~K}$ in average) for northern midlatitudes (Lindfors et al., 2011). When both ascending and descending passes are averaged together, the diurnal effect on the differences is even smaller. Thus, if there would be a systematic effect at all, it would be small. But even these small effects will average out over 10 years with
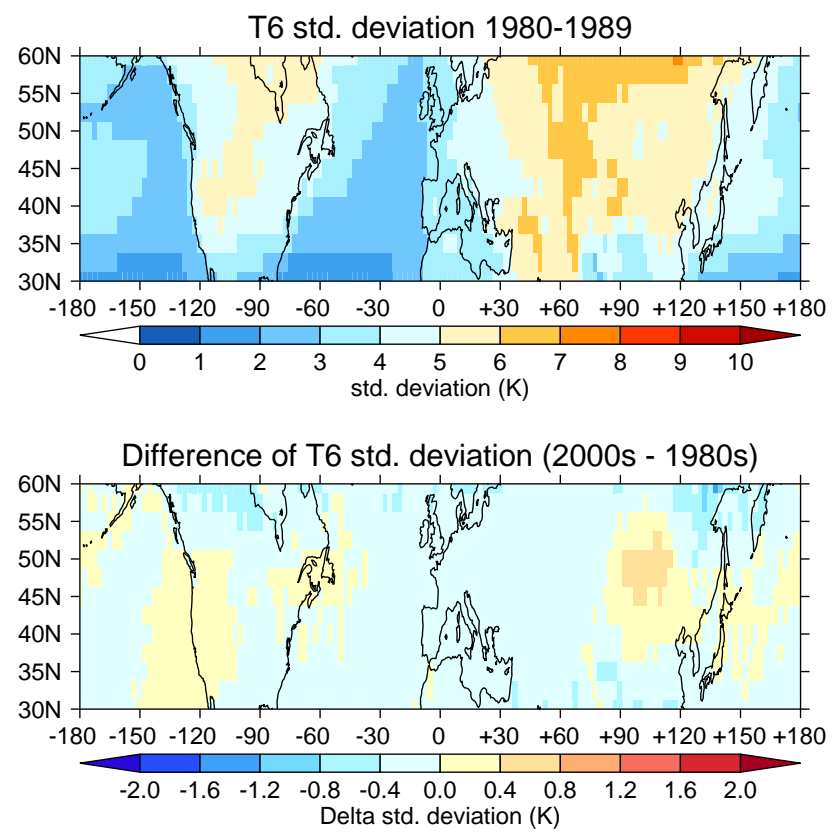

Levels of significance for the difference of the two means

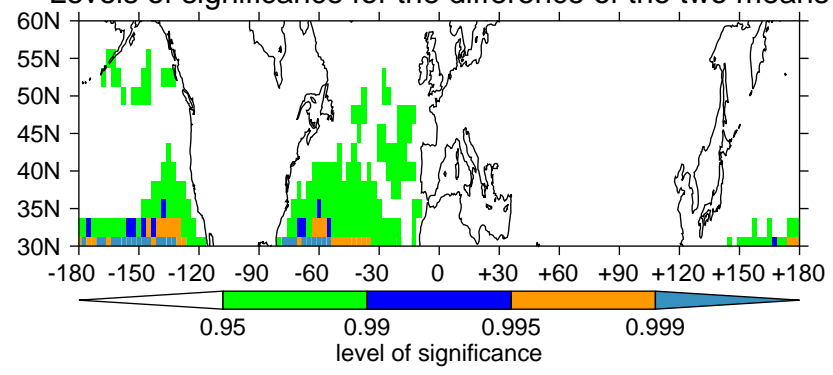

Figure 8. As Fig. 6, but for $T_{6}$.

many different satellites employed. Thus, we do not expect such an impact on the interdecadal change of the mean values of the brightness temperatures. The variances could grow if the satellite overpass times would vary more during the 2000s than the 1980s. But we see no reason to believe this and the standard deviations shown in Figs. 6 and 8 are much larger than the diurnal variations in the two considered channels. Thus, we deem our analysis is robust against a potential conspiracy of orbit drifts and diurnal temperature variations.

We have also checked whether the so-called clear-sky bias (John et al., 2011) has an influence on our results. For short time periods this can indeed be a problem, since on a daily basis there are large gaps in the data, because of clouds or other reasons. About half of the $2.5^{\circ} \times 2.5^{\circ}$ grid boxes are flagged as missing or invalid data. On a monthly basis the gaps are reduced considerably to about $5 \%$. We can expect therefore that the gaps are reduced even more on annual and decadal bases (not tested). The gaps are of similar extent in both decades considered. This does not provide strong arguments to assume the clear-sky bias distorting our results. 


\section{Summary and outlook}

We have used 30 years of intercalibrated data of HIRS brightness temperatures to derive a corresponding data set of upper tropospheric humidity. We used the method described by Jackson and Bates (2001) to determine $\mathrm{UTH}_{\mathrm{i}}$ from two brightness temperatures, $T_{12}$ and $T_{6}$. In doing so, we could directly use the coefficients provided by these authors for $T_{12}$, since a set of channel 12 brightness temperatures intercalibrated to the HIRS version 2 on NOAA-12 was already available (Shi et al., 2008). Yet for $T_{6}$ we only had a complete data set intercalibrated to HIRS version 4 on METOP-A. This implied that the original coefficients $a^{\prime}$ and $b^{\prime}$ of Jackson and Bates (2001) could not be used anymore. We solved this problem and determined new coefficients $a^{\prime \prime}$ and $b^{\prime \prime}$ by a linear regression between all $T_{6}$ data measured with HIRS/2 on NOAA-12, $T_{6 / 2}$, and their counterpart values intercalibrated to HIRS/4, $T_{6 / 4}$. This resulted eventually in Eq. (3), which gives $\mathrm{UTH}_{\mathrm{i}}$ as a function of $T_{12 / 2}$ and $T_{6 / 4}$.

Using this we have produced daily data files with $\mathrm{UTH}_{\mathrm{i}}$, $T_{12 / 2}$, and intercalibrated $T_{6 / 2}$ based on the regression from $T_{6 / 4}$ for the Northern Hemisphere midlatitude zone 30 $60^{\circ} \mathrm{N}$. These raw data have then been regridded to $2.5^{\circ} \times 2.5^{\circ}$ resolution, and monthly means files have been produced. These have in turn been used for a first application to calculate decadal means for the decades 1980-1989 and 20002009. The difference field of these means, the standard deviations of the 120 monthly mean values for each grid box and each decade, and the statistical significance of the change of the means has been determined. It turned out that $\mathrm{UTH}_{\mathrm{i}}$ increased at many locations by a few percent with large statistical significance, whereas the brightness temperature means changed often insignificantly. The significance of the change in the means of $\mathrm{UTH}_{\mathrm{i}}$ is mainly explained by an increase in the variance of the brightness temperature distributions at many locations. We note again that all these steps can be performed for $\mathrm{UTH}_{\mathrm{w}}$ in the same way, one has merely to use the appropriate coefficients $(a, b)$ from Table 2 of Jackson and Bates (2001).
Such evaluations can of course readily be extended to the whole globe and this will be done in the near future. We have restricted our study to the midlatitudes because it served as a first test and because of our prime interest in the occurrence of ice supersaturation, which HIRS channel 12 detects mainly in the extratropics (because it is sensitive between roughly 300 and $500 \mathrm{hPa}$ ). For studies of $\mathrm{UTH}_{\mathrm{i}}$ itself such a restriction is not necessary. Further plans are to study the variability of $\mathrm{UTH}_{\mathrm{i}}$ on different time and space scales. The analysis should include short and longer-term variations, e.g. seasonal, El Niño-Southern Oscillation, North Atlantic Oscillation, solar cycle and long-term trends. Although classically ice-supersaturated regions have been defined as cloudfree regions, they are clearly related to cirrus cloud formation and contrail persistence. Thus, infrared-sounder measurements, which are necessarily cloud-cleared, should be combined with microwave-sounder data $(183.1 \mathrm{GHz}$, Buehler et al., 2008), which can be used in cloudy scenes as well. Furthermore, satellite data with stated higher vertical resolution as AIRS (Atmospheric Infrared Sounder) and IASI (Infrared Atmospheric Sounding Interferometer) will be profitable for a study of ice-supersaturated regions since the latter are only a few $100 \mathrm{~m}$ shallow on average.

In terms of ice supersaturation we especially want to know whether there is a trend in the frequency of occurrence of ice supersaturation and if so, if it is statistically significant; and whether the mean supersaturation and the occurrence frequency of extreme values are changing. Since natural cirrus formation requires quite high supersaturation values, answers to these questions are directly relevant to our expectations of the development of cirrus cloudiness in a future warmer climate. 


\section{Appendix A: Error calculation}

We provide here the formulae for calculation of the error of the resulting UTH due to errors in the brightness temperatures, $T_{12}$ and $T_{6}$. The total derivative of UTH is

$\mathrm{dUTH}=\frac{\partial \mathrm{UTH}}{\partial T_{6}} \mathrm{~d} T_{6}+\frac{\partial \mathrm{UTH}}{\partial T_{12}} \mathrm{~d} T_{12}$,

with the partial derivatives

$$
\frac{\partial \mathrm{UTH}}{\partial T_{6}}=\frac{-b^{\prime} \exp \left(a+b T_{12}\right)}{\left(a^{\prime}+b^{\prime} T_{6}\right)^{2}}=\mathrm{UTH} \frac{-b^{\prime}}{a^{\prime}+b^{\prime} T_{6}}
$$

and

$\frac{\partial \mathrm{UTH}}{\partial T_{12}}=\frac{b \exp \left(a+b T_{12}\right)}{a^{\prime}+b^{\prime} T_{6}}=\mathrm{UTH} b$.

Note that $b$ and $b^{\prime}$ are negative, thus $\partial \mathrm{UTH} / \partial T_{6}>0$ while $\partial \mathrm{UTH} / \partial T_{12}<0$. Further, both $a+b T_{12}$ and $a^{\prime}+b^{\prime} T_{6}$ decrease with increasing brightness temperature because of the negative values of $b$ and $b^{\prime}$. Thus, $\partial \mathrm{UTH} / \partial T_{12}$ approaches zero from below for $T_{12} \rightarrow 270 \mathrm{~K}$ (consistent with Fig. 13 of Jackson and Bates, 2001, lower part) while $\partial \mathrm{UTH} / \partial T_{6}$ must increase for $T_{6} \rightarrow 270 \mathrm{~K}$ (as in our Fig. 2, but inconsistent with Fig. 13 of Jackson and Bates, 2001, upper part).

The relative error of UTH is proportional to the relative error of $T_{6}$ and proportional to the absolute uncertainty of $T_{12}$,

$\left(\frac{\Delta \mathrm{UTH}}{\mathrm{UTH}}\right)=\frac{-b^{\prime} T_{6}}{a^{\prime}+b^{\prime} T_{6}} \cdot\left(\frac{\Delta T_{6}}{T_{6}}\right)+b \Delta T_{12}$.

The first right-hand side term is what is shown in our Fig. 2, that is, it is equivalent to $\Delta\left(1 / P_{H}\right) /\left(1 / P_{H}\right)$, the relative error of $\left(1 / P_{H}\right)$. For use with Eq. (3) we have simply to replace the single-primed with the double-primed coefficients, but the differences are very small. The uncertainty in channel 12 contributes typically about five times as much to the relative error of UTH than the uncertainty in channel 6. 
Acknowledgements. K. Eleftheratos thanks DAAD (Deutscher Akademischer Austauschdienst) for a scholarship that allowed performing this work at DLR's Institute of Atmospheric Physics.

The service charges for this open access publication

have been covered by a Research Centre of the

Helmholtz Association.

Edited by: A. Petzold

\section{References}

Buehler, S., Kuvatov, M., John, V., Milz, M., Soden, B., Jackson, D., and Notholt, J.: An upper tropospheric humidity data set from operational satellite microwave data, J. Geophys. Res., 113, D14110, doi:10.1029/2007JD009314, 2008.

Chen, R., Cao, C., and Menzel, W.: Intersatellite calibration of NOAA HIRS $\mathrm{CO}_{2}$ channels for climate studies, J. Geophys. Res., 118, 5190-5203, doi:10.1002/jgrd.50447, 2013.

Dickson, N., Gierens, K., Rogers, H., and Jones, R.: Vertical spatial scales of ice supersaturation and probability of ice supersaturated layers in low resolution profiles of relative humidity, in: Proceedings of the 2nd International Conference on Transport, Atmosphere and Climate, edited by: Sausen, R., van Velthoven, P., Brüning, C., and Blum, A., DLR Forschungsbericht 2010-10, 239-243, 2010.

Gettelman, A., Fetzer, E., Elderling, A., and Irion, F.: The global distribution of supersaturation in the upper troposphere from the Atmospheric Infrared Sounder, J. Climate, 19, 6089-6103, 2006.

Gierens, K., Kohlhepp, R., Spichtinger, P., and SchroedterHomscheidt, M.: Ice supersaturation as seen from TOVS, Atmos. Chem. Phys., 4, 539-547, doi:10.5194/acp-4-539-2004, 2004.

Gierens, K., Spichtinger, P., and Schumann, U.: Ice supersaturation, in: Atmospheric Physics. Background - Methods - Trends, edited by: Schumann, U., chap. 9, 135-150, Springer, Heidelberg, Germany, 2012.

Jackson, D. and Bates, J.: A 20-yr TOVS radiance Pathfinder data set for climate analysis, in: 10th Conference on Satellite Meteorology and Oceanography, 80th AMS Annual Meeting, Long Beach, CA, JP4.11, 1-4, 2000.

Jackson, D. and Bates, J.: Upper tropospheric humidity algorithm assessment, J. Geophys. Res., 106, 32259-32270, 2001.

John, V., Holl, G., Allan, R., Buehler, S., Parker, D., and Soden, B.: Clear sky biases in satellite infrared estimates of upper tropospheric humidity and its trends, J. Geophys. Res., 116, D14108, doi:10.1029/2010JD015355, 2011.
Lindfors, A., Mackenzie, I., Tett, S., and Shi, L.: Climatological diurnal cycles in clear-sky brightness temperatures from the Highresolution Infrared Radiation Sounder (HIRS), J. Atmos. Ocean. Tech., 28, 1199-1205, 2011.

NOAA and NASA-GSFC: NOAA-N Prime, Tech. Rep. Document No. NP-2008-10-056-GSFC, NOAA and NASA-GSFC, 2008.

Rädel, G. and Shine, K.: Evaluation of the use of radiosonde humidity data to predict the occurrence of persistent contrails, Q. J. Roy. Meteorol. Soc., 133, 1413-1423, 2007.

Shi, L.: Intersatellite differences of HIRS longwave channels between NOAA-14 and NOAA-15 and between NOAA-17 and METOP-A, IEEE T. Geosci. Remote, 51, 1414-1424, 2013.

Shi, L. and Bates, J.: Three decades of intersatellite-calibrated High-Resolution Infrared Radiation Sounder upper tropospheric water vapor, J. Geophys. Res., 116, D04108, doi:10.1029/2010JD014847, 2011.

Shi, L., Bates, J., and Cao, C.: Scene radiance dependent intersatellite biases of HIRS longwave channels, J. Atmos. Ocean. Tech., 25, 2219-2229, doi:10.1175/2008JTECHA1058.1, 2008.

Soden, B. and Bretherton, F.: Upper tropospheric relative humidity from the GOES $6.7 \mu \mathrm{m}$ channel: Method and climatology for July 1987, J. Geophys. Res., 98, 16669-16688, 1993.

Spichtinger, P., Gierens, K., Leiterer, U., and Dier, H.: Ice supersaturation in the tropopause region over Lindenberg, Germany, Meteorol. Z., 12, 143-156, 2003a.

Spichtinger, P., Gierens, K., and Read, W.: The global distribution of ice-supersaturated regions as seen by the Microwave Limb Sounder, Q. J. Roy. Meteorol. Soc., 129, 3391-3410, 2003 b.

Treffeisen, R., Krejci, R., Ström, J., Engvall, A. C., Herber, A., and Thomason, L.: Humidity observations in the Arctic troposphere over Ny-Ålesund, Svalbard based on 15 years of radiosonde data, Atmos. Chem. Phys., 7, 2721-2732, doi:10.5194/acp-7-27212007, 2007.

Weatherhead, E., Reinsel, G., Tiao, G., Meng, X.-L., Choi, D., Cheang, W.-K., Keller, T., DeLuisi, J., Wuebbles, D., Kerr, J., Miller, A., Oltmans, S., and Frederick, J.: Factors affecting the detection of trends: Statistical considerations and applications to environmental data, J. Geophys. Res., 103, 17149-17161, doi:10.1029/98JD00995, 1998.

Zerefos, C. S., Tourpali, K., Eleftheratos, K., Kazadzis, S., Meleti, C., Feister, U., Koskela, T., and Heikkilä, A.: Evidence of a possible turning point in solar UV-B over Canada, Europe and Japan, Atmos. Chem. Phys., 12, 2469-2477, doi:10.5194/acp-12-24692012, 2012. 